\title{
Clinical Exercise Testing
}




\section{Progressin \\ Respiratory Research}

Vol. 32

Chris T. Bolliger, Cape Town

KARGER $\begin{aligned} & \text { Basel } \cdot \text { Freiburg } \cdot \text { Paris } \cdot \text { London } \cdot \text { New York } \\ & \text { New Delhi } \cdot \text { Bangkok } \cdot \text { Singapore } \cdot \text { Tokyo } \cdot \text { Sydney }\end{aligned}$ 


\section{Clinical Exercise Testing}

Volume Editors

Idelle M. Weisman, El Paso, Tex.

R. Jorge Zeballos, El Paso, Tex.

83 figures, 10 in color, and 97 tables, 2002

KARGER $\begin{aligned} & \text { Basel } \cdot \text { Freiburg } \cdot \text { Paris } \cdot \text { London } \cdot \text { New York } \cdot \\ & \text { New Delhi } \cdot \text { Bangkok } \cdot \text { Singapore } \cdot \text { Tokyo } \cdot \text { Sydney }\end{aligned}$ 


\section{Idelle M. Weisman, MD}

Human Performance Laboratory Department of Clinical Investigation Pulmonary-Critical Care Service William Beaumont Army Medical Center El Paso, Tex.

and

Department of Medicine Pulmonary-Critical Care Division

University of Texas Health Science Center at San Antonio San Antonio, Tex., USA

\section{R. Jorge Zeballos, MD, DMSc}

Department of Anesthesia

Texas Tech Regional Health Science Center

and

Human Performance Laboratory

Department of Clinical Investigation

William Beaumont Army Medical Center

El Paso, Tex., USA

\section{Library of Congress Cataloging-in-Publication Data}

Clinical exercise testing / volume editors, Idelle M. Weisman, R. Jorge Zeballos.

p. ; cm. - (Progress in respiratory research, ISSN 1422-2140; v. 32)

ncludes bibliographical references and index.

ISBN 3805572980 (hardcover : alk. paper)

1. Exercise tests. 2. Lungs - Diseases - Diagnosis. 3. Cardiopulmonary system - Diseases - Diagnosis.

I. Weisman, Idelle M. II. Zeballos, R. Jorge. III. Series.

[DNLM: 1. Exercise Test. WG 141.5.F9 C641 2002]

RC734.E87.C554 2002

$616.1^{\prime} 075-\mathrm{dc} 21$

Bibliographic Indices. This publication is listed in bibliographic services, including Current Contents ${ }^{\circledR}$ and Index Medicus.

Drug Dosage. The authors and the publisher have exerted every effort to ensure that drug selection and dosage set forth in this text are in accord with current recommendations and practice at the time of publication. However, in view of ongoing research, changes in government regulations, and the constant flow of information relating to drug therapy and drug reactions, the reader is urged to check the package insert for each drug for any change in indications and dosage and for added warnings and precautions. This is particularly important when the recommended agent is a new and/or infrequently employed drug.
All rights reserved. No part of this publication may be translated into other languages, reproduced or utilized in any form or by any means, electronic or mechanical, including photocopying, recording, microcopying, or by any information storage and retrieval system, without permission in writing from the publisher.

(C) Copyright 2002 by S. Karger AG,

P.O. Box, CH-4009 Basel (Switzerland)

www.karger.com

Printed in Switzerland on acid-free paper by

Reinhardt Druck, Basel

ISBN 3-8055-7298-0, ISSN 1422-2140 


\section{Contents}

VII Foreword

IX Preface

1 Cardiovascular and Respiratory System Responses and Limitations to Exercise Rodman, J.R.; Haverkamp, H.C.; Gordon, S.M.; Dempsey, J.A.

18 Muscular Alterations in Chronic Obstructive Pulmonary Disease and Chronic Heart Failure at Rest and during Exercise

Gosker, H.R.; Uszko-Lencer, N.H.M.K.; Wouters, E.F.M.; van der Vusse, G.J.; Schols, A.M.W.J.

30 Modalities of Clinical Exercise Testing

Zeballos, R.J.; Weisman, I.M.

43 Methods for Cardiopulmonary Exercise Testing

Beck, K.C.; Weisman, I.M.

60 Deconditioning, and Principles of Training

Troosters, T.; Gosselink, R.; Decramer, M.

72 Mechanisms and Measurement of Exertional Dyspnea Mahler, D.A.; Fierro-Carrion, G.; Baird, J.C.

81 Cardiopulmonary Exercise Testing in Unexplained Dyspnea Gay, S.E.; Weisman, I.M.; Flaherty, K.R.; Martinez, F.J.

89 Respiratory System Responses to Exercise in Aging Johnson, B.D.

99 Evolving Role of Cardiopulmonary Exercise Testing in Heart Failure and Cardiac Transplantation

Agostoni, P.; Guazzi, M.

109 Noninvasive Exercise Testing Modalities for Ischemia Strelich, K.; Bach, D.S.

120 Role of Cardiac Rehabilitation in Heart Failure and Cardiac Transplantation Braith, R.W.; Edwards, D.G.

138 Exercise Limitation and Clinical Exercise Testing in Chronic Obstructive Pulmonary Disease O'Donnell, D.E.

159 The Importance of Exercise Training in Pulmonary Rehabilitation Celli, B.R. 
173 Functional Evaluation in Lung Volume Reduction Surgery

Sciurba, F.C.; Patel, S.A.

186 Cardiorespiratory Responses during Exercise in Interstitial Lung Disease

Krishnan, B.S.; Marciniuk, D.D.

200 Role of Cardiopulmonary Exercise Testing in Patients with Pulmonary Vascular Disease Systrom, D.M.; Cockrill, B.A.; Hales, C.A.

205 Asthma and Exercise

Tan, R.A.; Spector, S.L.

217 Evaluation of Impairment and Disability: The Role of Cardiopulmonary Exercise Testing Sue, D.Y.

231 Role of Cardiopulmonary Exercise Testing in the Preoperative Evaluation for Lung Resection Diacon, A.H.; Bolliger, C.T.

242 The Role of Cardiopulmonary Exercise Testing for Patients with Suspected Metabolic Myopathies and Other Neuromuscular Disorders

Flaherty, K.R.; Weisman, I.M.; Zeballos, R.J.; Martinez, F.J.

254 Role of Cardiopulmonary Exercise Testing in Lung and Heart-Lung Transplantation Williams, T.J.; Slater, W.R.

264 Exercise Responses in Systemic Conditions

Obesity, Diabetes, Thyroid Disorders, and Chronic Fatigue Syndrome

Sietsema, K.E.

273 Clinical Exercise Testing during Pregnancy and the Postpartum Period

O'Toole, M.L.; Artal, R.

282 Clinical Exercise Testing in Children

Fahey, J.; Nemet, D.; Cooper, D.M.

300 An Integrative A pproach to the Interpretation of Cardiopulmonary Exercise Testing Weisman, I.M.; Zeballos, R.J.

323 Author Index

324 Subject Index 


\section{Foreword}

Clinical exercise testing has been an area of personal interest for me for many years. It could therefore only have been a matter of time until I would have liked to see a volume in the book series Progress in Respiratory Research dedicated to this topic. Volume 32 is the result of this desire. The most important thing in the initial planning phase was, as always, to find the ideal volume editor(s), respected scientists in the field who can deliver the goods in time. Until now we have always been lucky in this respect. For this 32 nd volume I did not have to think a long time who I was going to ask. Idelle Weisman, one of the outstanding experts in Cardiopulmonary Exercise Testing (CPET), came to my mind almost immediately. I have known her for some years now and have always admired her knowledge but at least as much her continued enthusiasm for both research in and teaching of CPET. When I approached her she immediately accepted the task, but asked me to do it together with her long-time colleague, Jorge Zeballos, a further name which does not need introduction. Their choice of chapter authors united a team of recognized specialists in their respective field.

The set was almost a guarantee for success. From there to the finished book, however, it took a lot of staying power by everyone to get everything done on time.
Dear Reader, when you look at the final product you will easily see what a high-powered book you are holding in your hands. In 25 well-written chapters all the relevant information about CPET is covered, from the physiologic responses to exercise, the set-up of an exercise lab, the methodology of clinical exercise testing, the varying patterns of response to exercise in different disease states, and very importantly to the clinical applications, everything you might want to know has been covered. As you read the book you will easily understand why CPET is becoming increasingly more important to help in clinical decision-making in the management of patients. The book is a must for anyone interested in clinical exercise testing.

Again, the publisher, S. Karger AG, Basel, Switzerland, has done a great job in bringing out a very attractive book with excellent quality of print. The appealing appearance of each single volume of Progress in Respiratory Research continues to be another key factor for the ever increasing success of the 'blue' book series. I would like to express a sincere thank you to Idelle and Jorge, to all chapter contributors, as well as to the staff at Karger.

C.T. Bolliger, Series Editor 


\section{Preface}

Clinical Exercise Testing is increasingly being used in clinical medicine, as functional assessment has become an integral component of patient evaluation; this reflects in part a growing awareness of the limitations of traditional resting cardiopulmonary measurements in reliably estimating functional performance and outcome. A spectrum of clinical exercise testing modalities is available; which test to use depends on the question(s) being asked and the available resources. In turn, Cardiopulmonary Exercise Testing (CPET) has gained increasing popularity with a wide spectrum of clinical application over the last 25 years because of the valuable information it provides in patient diagnosis and management. This issue of Progress in Respiratory Research is testimony to the expanding list of clinical applications.

We were very excited about the Progress in Respiratory Research issue on Clinical Exercise Testing, as it would provide an opportunity for presentation of a comprehensive interdisciplinary update by well-respected experts that would focus on clinical application and highlight recent developments/practices based on current scientific knowledge and technologic advances. For CPET this would also reinforce the importance/value of the integrative exercise response in clinical assessment; that is, the ability to quantitate the patient's whole exercise response as well as contributions and interactions of individual components and thereby provide answers to questions not possible from other clinical exercise testing modalities. This issue explores the most widely used clinical exercise testing modalities with an emphasis on CPET. Furthermore, these comprehensive albeit succinct and cogent updates will be particularly useful to clinical readers chal-
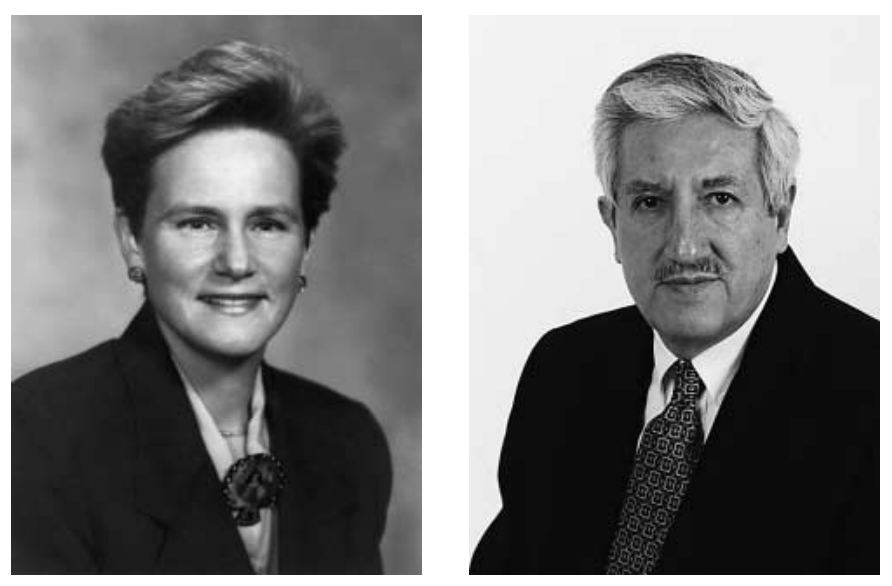

lenged with keeping up with the remarkable information expansion in this area and the on-going need to assess clinical relevancy.

The expert contributors to this issue have provided timely, clinically oriented, and practical updates/reviews, which together represent a well-balanced perspective of clinical exercise testing for the new millennium. In that regard, we believe that this issue will be helpful to a wide audience - pulmonologists, cardiologists, pediatricians, exercise physiologists, rehabilitation specialists, respiratory therapists, etc. This issue begins with a state-of-the-art review of exercise physiology and limitation to exercise in normal subjects and is followed by a chapter on skeletal muscle function and energy metabolism during exercise which is currently a very 'hot' investigational topic. Modalities of clinical exercise testing provides a low-tech to 
high-tech functional assessment overview which concentrates on the 6-minute walk test, the shuttle test, and stair climbing, and addresses when these and more high-tech tests including graded exercise testing and CPET would be appropriately used. This is followed by a chapter providing basic and practical information related to equipment, methodology, protocols, conduct of the test, and also addresses important quality control issues for CPET. An article on deconditioning and training highlights the physiologic response to training and relates current knowledge to practical considerations for clinical application.

Since exertional dyspnea is a common reason for referral for exercise testing, mechanisms and measurement of dyspnea are also discussed. Another chapter addresses the patient with unexplained dyspnea after initial non-diagnostic work-up and emphasizes the role of CPET used as part of a step approach in the assessment of these challenging cases. A chapter on the aging pulmonary system and exercise provides insight and information that is extremely relevant as increasing numbers of senior citizens exercise.

Subsequent discussions evaluate exercise testing in different patient populations. A trio of complimentary chapters addresses important cardiovascular topics - the role of CPET in heart failure and transplantation discusses physiologic responses and current drug therapies, the role of cardiac rehabilitation in heart failure and cardiac transplantation discusses exercise prescription and monitoring and to complete the picture, non-invasive exercise testing modalities for ischemia discusses the most current technologies and clinical decision analysis for their use. A trio of chapters comprehensively evaluates important COPD topics including the role of CPET in evaluating exercise intolerance, exercise response patterns, exercise limitation, exercise training, and functional evaluation in lung volume reduction surgery. The next two chapters address the role of CPET in Interstitial Lung Disease and in Pulmonary Vascular Disease and a third discusses asthma and exercise.

This is followed by articles evaluating the use of exercise testing in specific clinical settings: in the evaluation of Impairment-Disability; in the Preoperative Evaluation for lung resection; in the evaluation of patients with metabolic myopathy and other neuromuscular disorders; in the evaluation of patients with Lung and Heart-Lung Transplantation, and in the evaluation of patients with other systemic diseases including obesity, diabetes, hyperthyroidism and chronic fatigue syndrome.

Previous monographs on clinical exercise testing have not included chapters on important population cohorts including pregnant/post-partum women and children, which have been included in this issue. Importantly, the chapter on exercise in children will appeal not only to pediatricians and pediatric sub-specialists, but also to adult pulmonologists and cardiologists who will provide care for the increasing number of children surviving into adulthood.

The subject of the last chapter is interpretation of cardiopulmonary exercise testing, which uses illustrative case studies to highlight the integrative approach to cardiopulmonary exercise testing and its role in the clinical decision-making process. Finally, it should be noted that most of these articles were written within the last 6 months of 2001 and includes 'hot-off-the-press' information that will remain clinically relevant for some time.

Our vision for this issue was to demonstrate how the information obtained from cardiopulmonary exercise testing impacts and enhances the clinical decision-making process including diagnosis, prognosis, severity, progression, and response to treatment in different clinical settings. Furthermore, we wanted to demonstrate how CPET complements and enhances other diagnostic modalities and can be an integral component in the clinical decisionmaking process. Enormous progress has been made but CPET still remains underutilized. Hopefully, the contents of this issue will stimulate more widespread use and discussion so that the full potential and limitations of cardiopulmonary exercise testing in the clinical decision-making process will be realized.

\section{Acknowledgements}

We are grateful to S. Karger AG, Switzerland and to Chris Bolliger, Editor of the Progress in Respiratory Research series, for allowing us the opportunity to assemble this outstanding group of articles. We believe that they will be a valuable resource and will appeal to a broad spectrum of readers interested in clinical exercise testing - from those who order exercise tests to answer important clinical questions to those who perform the testing. We would also like to express our appreciation to the expert contributors for their efforts to make this an updated 'state-of-the-art' book in Clinical Exercise Testing.

Special thanks are extended to Raul Hernandez, David Lopez and Luz Torres at William Beaumont Army Medical Center, El Paso, Texas, for their diligence and dedication in helping me complete this project. We would like to thank the command at William Beaumont Army Medical Center for their support in completing this project, and all colleagues who over the years have referred patients to the Human Performance Laboratory so that we might contribute to the clinical decision-making process. Finally, this issue is dedicated to our families for their patience, tolerance and ongoing support.

Idelle M. Weisman, R. Jorge Zeballos, Volume Editors
X

Preface 